\title{
Intraosseous Transmigration of Mandibular Premolar into the Mandibular Ramus: A Case Report
}

ISSN: 2637-7764

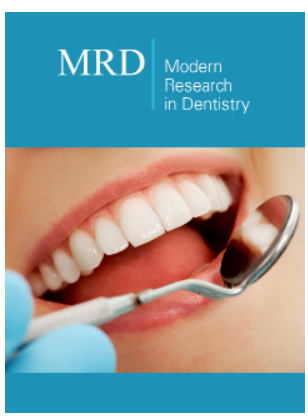

*Correspondingauthor:Auric Bhattacharya, Assistant Professor, Department of Oral and Maxillofacial Surgery, Melaka Manipal Medical College, Malaysia

\section{Submission: 非 August 08, 2020}

Published: 䟱April 26, 2021

Volume 6 - Issue 2

How to cite this article: Anand Francis Farias, Lynn Lilly Varghese, Kanwardeep kaur, Auric Bhattacharya. Intraosseous Transmigration of Mandibular Premolar into the Mandibular Ramus: A Case Report. Mod Res Dent. 6(2). MRD. 000635. 2021. DOI:_10.31031/MRD.2021.06.000635

Copyright@ Auric Bhattacharya, This article is distributed under the terms of the Creative Commons Attribution 4.0 International License, which permits unrestricted use and redistribution provided that the original author and source are credited.

\author{
Anand Francis Farias, Lynn Lilly Varghese, Kanwardeep kaur and Auric \\ Bhattacharya*
}

Assistant Professor, Department of Oral and Maxillofacial Surgery, Melaka Manipal Medical College, Malaysia

\begin{abstract}
Background: Literature survey indicates that intraosseous transmigration is uncommon. Transmigration of mandibular premolars to distant sites like the ramus are rare and is often detected by chance.

Case description: A 19-year-old female reported seeking replacement of her missing teeth. Clinical examination showed multiple missing teeth and a history of early loss of permanent molars. Panoramic radiographs revealed a transmigrated mandibular premolar in the ramus of the mandible surrounded by well a circumscribed radiolucent area.
\end{abstract}

Practical implications: Transmigrated premolars in the ramus can cause complications like cystic lesions, weakened ramus, and susceptibility to fracture. Young females undergoing early extraction of permanent molars are at increased risk.

\section{Introduction}

Intrabony migration of impacted teeth is a rare phenomenon of unknown etiology. Peck has reported that the most common teeth to transmigrate are the Mandibular Canines followed by the Mandibular Second Premolars [1]. The estimated prevalence rate is $0.2 \%$ for the mandibular second premolar [2]. Studies have suggested that there is female predilection. 2, 3 These teeth migrate distally and have been found in the mandibular ramus and coronoid processes. Unilateral transmigrations are more common [3-5].

Ectopia is defined as "an abnormal congenital or acquired position of an organ or part". Ectopic tooth eruption is defined as "a condition in which the permanent teeth, because of deficiency of growth in the jaw or segment of the jaw, assume a path of eruption that intercepts a primary tooth, causes its premature loss and produces a consequent malposition of the permanent tooth" [6]. The term "transmigration" is however, the term assigned to ectopia when the teeth are present in areas distant from the alveolar process [4].

\section{Case Report}

A 19-year-old Chinese female patient reported to the outpatient department requesting for the replacement of her missing upper and lower back teeth. History revealed that the teeth were extracted approximately 6 years ago due to dental caries. Clinical examination revealed that four teeth were missing in the maxillary arch $(1,2,5,12)$ and seven teeth missing in the mandibular arch $(17,18,19,20,30,31,32)$. When informed, the patient insisted that her maxillary right second molar had never erupted and that she had had only four teeth extracted in her lower arch. The disparity in clinical findings, patient's history and a need for comprehensive prosthodontic treatment planning necessitated further radiographic investigation.

The panoramic radiograph revealed a transmigrated mandibular second premolar vertically impacted in the left ramus, closer to the anterior border. The crown was facing the sigmoid notch. The root appeared to be completely formed and parallel to the anterior border of the ramus. A radiolucent area was visible surrounding the crown suggesting a possible bony crypt (Figure 1). The tooth was asymptomatic. 


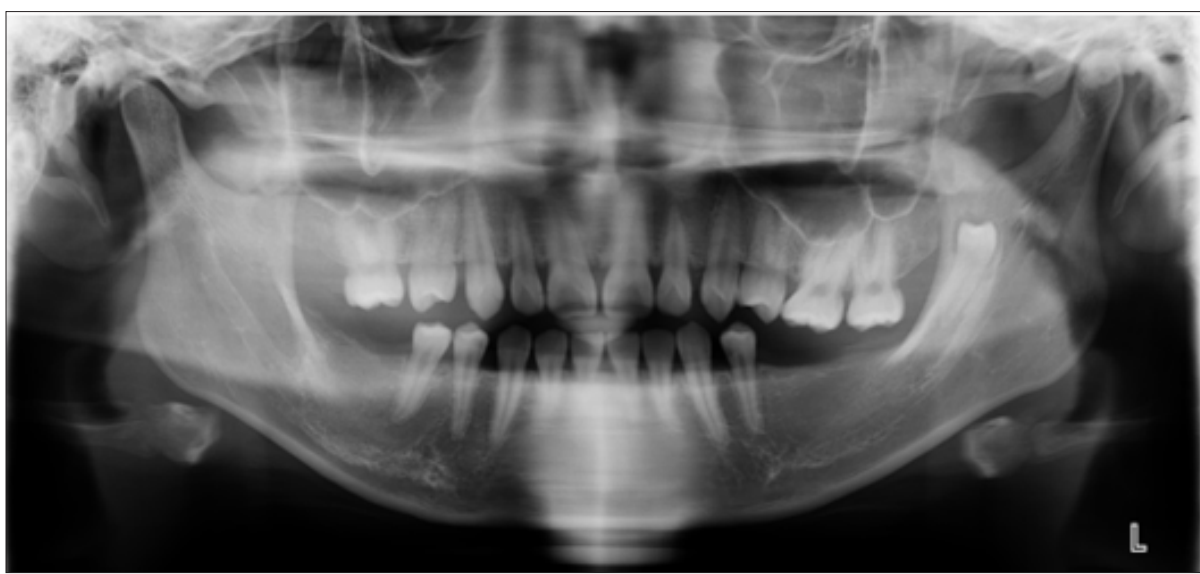

Figure 1: Panoramic radiograph showing the transmigrated left $2^{\text {nd }}$ Premolar in the ramus.

\section{Discussion}

Intraosseous transmigration of the mandibular premolar is a rare occurrence with few reported cases in the dental literature [48]. Asymptomatic Transmigration of the teeth poses a diagnostic challenge, as these teeth are not routinely visible during a clinical examination or in routine periapical radiographs. Panoramic radiographs or CBCT are recommended as a diagnostic tool [9]. In the present case, transmigration of missing mandibular second premolar was a chance finding. It was noticed when panoramic radiograph was taken to assess the status of the remaining teeth and bone for a prosthetic treatment plan.

Impacted teeth when left undetected can lead to complications like cystic lesions, neoplasm, temporomandibular joint disorders and weakening of ramus, which could increase susceptibility to fracture. The distally transmigrated mandibular second premolar was housed in the mid-portion of the left ramus. This is comparable to other reported cases of transmigration of mandibular second premolar to the same location $[4,5,10]$.

Several theories have been proposed to explain the transmigration $[9,11,12]$. The most likely explanation for transmigration in the present case could be the early loss of both the permanent molars. Shapira et al9 suggested that the developing tooth bud of the mandibular second premolar has a variable degree of distal inclination under the distal root of the primary deciduous molar. This distal angulation coupled with the early loss of the permanent first molar could contribute to transmigration. In the present case, the patient had experienced early removal of both mandibular molars, which possibly allowed for a transmigration path to the ramus of the mandible. The present case was a 19-yearold female Chinese patient. Mattesson et al. [2] reported that transmigration of mandibular premolar showed female predilection (1.7:1 ratio), but no age or racial predilection. Other reasons could be genetic predilection or idiopathic.

The treatment of a transmigrated tooth depends on the position of the tooth, symptoms, and infection. The treatment options include leaving the tooth in-situ if there is no infection or pain or surgical removal of the tooth if the patient reports pain or if there is evidence of cystic formations [1,4,7,8,13]. Early, detection of transmigrating tooth buds can be transplanted as a natural replacement in young patients with tooth loss [9]. In the present case, the patient did not report pain, but the presence of bony crypt warrants a careful observation. Hence, it was decided to leave the tooth in position and observe the patient during the follow-up phase of her treatment.

\section{Conclusion}

Removal of the mandibular molars before the eruption of the mandibular second premolars is a likely cause for transmigration of the unerupted second premolar. Hence, young female patients who undergo early extraction of permanent first molar should be monitored carefully.

\section{References}

1. Peck S (1998) On the phenomenon of intraosseous migration of nonerupting teeth. Am J Orthod Dentofacial Orthop 113(5): 515-517.

2. Matteson SR, Kantor ML, Proffit WR (1982) Extreme distal migration of the mandibular second bicuspid. A variant of eruption. Angle Orthod 52(1): 11-18.

3. Sutton PR (1968) Migrating nonerupted mandibular premolars: A case of migration into the coronoid process. Oral Surg Oral Med Oral Pathol 25(1): 87-98.

4. Alves DB, Pedrosa EF, Andreo JC, Carvalho LM, Rodrigues AC (2008) Transmigration of mandibular second premolar in a patient with cleft lip and palate-case report. J Appl Oral Sci 16(5): 360-363.

5. Nelson G (1997) Journey through time. Am J Orthod Dentofacial Orthop 111(4): 451-452.

6. Nikiforuk G (1948) Ectopic eruption: Discussion and clinical report. J Ont Dent Assoc 25: 243-246.

7. Okada H, Miyake S, Toyama K, Yamamoto H (2002) Intraosseous tooth migration of impacted mandibular premolar: Computed tomography observation of 2 cases of migration into the mandibular neck and the coronoid process. J Oral Maxillofac Surg 60(6): 686-689.

8. Infante Cossio P, Hernandez Guisado JM, Gutierrez Perez JL (2000) Removal of a premolar with extreme distal migration by sagittal osteotomy of the mandibular ramus: Report of case. J Oral Maxillofac Surg 58(5): 575-577.

9. Shapira Y, Kuftinec MM (2003) Intrabony migration of impacted teeth. Angle Orthod 73(6): 738-743. 
10. Loh HS, Ho KH (1986) Unerupted and ectopic mandibular premolars. Oral Surg Oral Med Oral Pathol 62(3): 358.

11. Shapira Y, Mischler WA, Kuftinec MM (1982) The displaced mandibular canine. J Dent Child 49(5): 362-364.
12. Miranti R, Levbarg M (1974) Extraction of a horizontally transmigrated impacted mandibular canine: report of case. J Am Dent Assoc 88(3): 607-610.

13. Lehman R (1987) A deviate eruption pattern. Am J Orthod Dentofacial Orthop 91(5): 427-428. 